\title{
Blood borne viruses
}

- key facts for primary

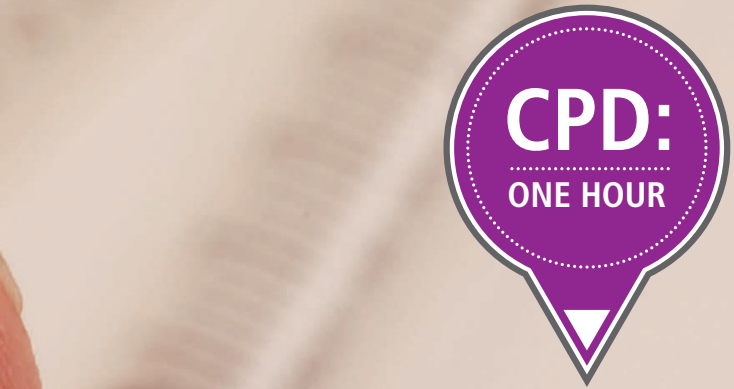

care dental teams

\section{R. Lala, ${ }^{1}$ C. Harwood, ${ }^{2}$ S. Eapen Simon, ${ }^{3}$ A. Lee ${ }^{4}$ and K. Jones ${ }^{5}$}

The purpose of this article is to support primary care dental teams with their legal, ethical and clinical responsibilities to provide fair access to dental services for people living with a blood borne virus and to manage their dental care effectively and appropriately.

People living with blood borne virus infections sometimes experience barriers accessing dental services. This may arise for a variety of reasons including misperceptions and misunderstanding by health practitioners of the risks of transmission during dental care.

People living with a blood borne virus who are otherwise well may be treated routinely in primary dental care without any change or restriction to the care that they receive.

\section{Blood borne viruses}

Blood borne viruses are transmitted through blood or other body fluids. The risk of transmission from saliva is minimal unless contaminated with blood. The most common blood borne viruses are human immunodeficiency virus (HIV), hepatitis $\mathrm{B}$ virus (HBV) and hepatitis $\mathrm{C}$ virus (HCV). All three viruses may cause serious and life threatening diseases, especially if diagnosed late or if untreated.

HIV attacks the immune system, weakening the body's ability to fight infections. In 2016, there were an estimated 89,400 people living with HIV in the UK. It is important to note that an estimated $12 \%$ of people are unaware of their HIV infection. ${ }^{1}$
Hepatitis B and C are viruses that infect the liver and if left unmanaged can cause liver failure and liver cancer. It is estimated that 214,000 people in the UK are living with chronic $\mathrm{HCV}^{2}$ In the UK, it is estimated that approximately 180,000 people are living with a chronic hepatitis B infection. ${ }^{3}$

These three infections are often insidious and can have chronic asymptomatic carrier states. Therefore, the risks of transmission to other people can be both hidden and protracted. The acute phase of hepatitis $\mathrm{B}$, when a person experiences symptoms, lasts between one and three months. However, many people with HBV will not experience any symptoms. Acute hepatitis $\mathrm{C}$ often does not have any symptoms. The latency period for HIV can be up ten years, during which people can be asymptomatic and unaware they have been infected.

People living with chronic hepatitis $\mathrm{C}$ can be treated successfully with a combination of two or three antiviral medications and achieve viral clearance. Chronic hepatitis B can be managed with antivirals to limit liver damage. However, this won't necessarily eliminate the infection and some people may need lifelong treatment. Antiretroviral therapy in people living with HIV can achieve viral suppression ie people's viral load can be reduced to an undetectable level.

\section{Routes of transmission}

Blood borne viruses can be transmitted when a susceptible individual is exposed to infected blood or other body fluids that carry the virus. This exposure can occur via broken tissues, mucous membranes or directly into the bloodstream. Therefore potential routes of

${ }^{7}$ Academic Clinical Lecturer, Academic Unit of Oral Health, Dentistry and Society, School of Clinical Dentistry, Claremont Crescent, Sheffield, S10 2TA; ${ }^{2}$ Specialty Registrar in Public Health, Leeds Teaching Hospitals NHS Trust, Health Education England Yorkshire and The Humber; ${ }^{3}$ Yorkshire and the Humber Screening and Immunisation Lead, Consultant in Dental Public Health, Public Health England - Yorkshire and the Humber Centre; ${ }^{4}$ Consultant in Communicable Disease Control, Public Health England and Reader in Public Health, University of Sheffield; ${ }^{5}$ Consultant in Dental Public Health, Public Health England 
transmission include direct exposure to infected bodily fluids, sexual contact, or from mother to baby during the period immediately before and after birth. Not everyone who is exposed to a blood borne virus will become infected.

\section{Occupational transmission}

Blood borne viruses are particularly important in primary care dentistry as they can be transmitted through exposure to bodily fluids (predominantly blood) containing the viruses.

Dental staff, especially those undertaking exposure-prone procedures, are at risk of transmission of blood borne viruses from infected patients. Needlestick injuries (30\% of exposures) and other sharps injuries (50\% of exposures) are the most common mechanisms of exposure in dental practice. There is also a risk of blood borne virus transmission from a bite or scratch, as well as mucocutaneous transmission such as eye splashes, though these are much less common. ${ }^{4}$

The observed rates of occupational blood borne virus transmission in healthcare workers following percutaneous exposure are significantly lower than the published estimates of risk of transmission. ${ }^{4}$ In fact, there has not been any reported transmission of HIV and HBV (Table 1). This is based on voluntary reports to the Public Health England surveillance system of significant occupational exposure. The difference is likely to be due to the success of the hepatitis B healthcare workers' immunisation programme and effective management of exposures thereby preventing transmission of blood borne viruses among healthcare workers. It is important that dental team members report incidents promptly to support accurate assessment of the risk of transmission and seroconversion (development of the antibodies for blood borne viruses). ${ }^{4}$

It is also important to note that if a person living with a blood borne virus achieves viral suppression through antiviral therapy, the risk of transmission to a healthcare worker through an exposure injury is greatly reduced, due to the suppressed viral load.

\section{Prevention}

The key ways to reduce blood borne virus transmissions are by preventing exposure in the first place and timely clinical management following any exposures. Preventive measures include: universal cross-infection precautions; hepatitis B virus immunisation for the dental team including post vaccination blood tests to verify adequate immunisation; implementing a robust sharps protocol; and a comprehensive dental practice infection control policy.

\section{Universal precautions}

Universal infection control precautions are the most effective way to minimise the transmission of blood borne viruses. This is because people may not know they are infected with a blood borne virus. Dental practices must have infection control policies and procedures that comply with the requirements of Department of Health best practice guidance Health Technical Memorandum 01-05: Decontamination in primary care dental practice. ${ }^{5}$

\section{Reduce susceptibility}

All new clinical staff must undergo standard health checks including being tested for $\mathrm{HIV}$ and HBV and HCV. There is a good vaccine against $\mathrm{HBV}$ that is $85-90 \%$ effective and national guidance states that all dental professionals should be immunised against HBV. Dental team members should seek occupational health advice regarding the latest information describing the hepatitis $\mathrm{B}$ vaccination procedure. ${ }^{6}$

\section{Continuing professional development}

Dental team registrants should be familiar with the enhanced continuing professional development (CPD) requirements to support General Dental Council (GDC) registration. ${ }^{8}$ The GDC highly recommends completing five hours of CPD in disinfection and decontamination in every CPD cycle as well as keeping up-to-date in complaints handling and legal and ethical issues. ${ }^{9}$

\section{Reduce transmission post exposure} In the event of an exposure, appropriate management can reduce the risk of transmission of a blood borne virus. Immediate management includes active bleeding of the wound (without sucking the wound) and washing the wound using soap and warm running water.

A risk assessment should be carried out based on the type of exposure and information about the source patient. Advice about post

\section{THERE IS ALSO A RISK OF BLOOD BORNE}

\section{VIRUS TRANSMISSION FROM A BITE OR}

\section{SCRATCH, AS WELL AS MUCOTANEOUS}

\section{TRANSMISSION SUCH AS EYE SPLASHES'}

\section{Local infection control policy}

The practice infection control policy should specify actions to take regarding personal protection and when personal protective equipment should be worn and changed. Personal protection includes hand hygiene and skin care and personal protective equipment includes disposable gloves, aprons, masks, face and eye protection and adequate footwear. ${ }^{5}$

\section{Sharps protocol}

Sharps injuries with hollow bore needles are the most commonly reported occupational exposure to blood borne viruses in a healthcare setting, though other sharps injuries are more common in a dental setting. For dental professionals sharps injuries are mostly sustained during a procedure. ${ }^{4}$ The Health and Safety (Sharp Instruments in Healthcare) Regulations 2013 provides guidance on the safe use of sharps. Dental practices must have written policies for sharps management, significant splashes to the eyes and broken skin.? exposure prophylaxis can be obtained from the local health protection team, hospital virology or microbiology services, occupational health services, hospital infection control officer or infectious disease or HIV teams. ${ }^{10}$ It is important that dental practice teams are aware of their local arrangements.

Post exposure prophylaxis within 72 hours is recommended when a healthcare worker experiences a blood exposure injury from a person thought to be infected with HIV. Starting the treatment as soon as possible is associated with improved effectiveness of post exposure prophylaxis.

The need for post exposure prophylaxis for hepatitis B depends on the hepatitis status of the source patient and the vaccination status of the exposed person. ${ }^{6}$ Management can include no treatment (if the exposed person has an adequate antibody response from a previous vaccine and the exposure is considered nonsignificant), hepatitis B immunoglobulin and vaccination boosters or full hepatitis $B$ vaccination series. ${ }^{6,11}$ 
Employers are legally required to make arrangements to deal with exposures, which include providing first aid facilities, access to post exposure prophylaxis and follow up through the occupational healthcare provider.

\section{Management of an infected healthcare worker}

All healthcare workers have an ethical and legal responsibility to protect the health and safety of themselves, colleagues and patients. Dental team members who are living with blood borne viruses must inform their line manager and should be supported to work in primary care dentistry. Confidential disclosure is encouraged. A potentially infected dental team member is responsible for seeking professional advice about the need to be tested if they believe they have been exposed to a blood borne virus infection through a work related incident or outside of the work environment. Expert advice from an occupational physician must be sought. ${ }^{12}$

The risk of transmission of HIV from an infected healthcare worker to the patient is considered to be extremely low to negligible. ${ }^{4,12}$ supervision of a consultant occupational physician and their treating physician, have their viral load monitored every three months and be registered with UK Advisory Panel Occupational Health Monitoring Register. ${ }^{12}$

\section{Legal and ethical responsibilities} Under the Equality Act $2010{ }^{13}$ people living with blood borne viruses are entitled to fair access and equitable care. Therefore, people living with blood borne viruses cannot be refused dental treatment or asked to attend a dental appointment at the end of the day, for example. Such practices are unlawful and clinically unnecessary.

Providers need to pay due regard to the Care Quality Commission (CQC) regulations 10 and 12 to ensure that people using a service are treated with respect and dignity and that infection control is aligned with HTM $01-$ 05. If appropriate universal infection control precautions are not undertaken the CQC can de-register practices and take action against them under criminal law, including prosecution. The GDC is also likely to be notified. ${ }^{14}$

\section{'DENTAL TEAM WORKERS LIVING WITH BLOOD}

\section{BORNE VIRUSES MUST INFORM THEIR LINE}

\section{MANAGER AND BE SUPPORTED TO}

\section{WORK IN PRIMARY CARE DENTISTRY'}

Dental professionals living with HIV can perform exposure prone procedures if they are on combination antiretroviral therapy and have a plasma viral load that is less than 200 copies per millilitre. ${ }^{12}$

Dental professionals living with hepatitis $\mathrm{B}$ can perform exposure prone procedures whilst taking continuous oral antiviral therapy if they are hepatitis B e antigen negative and have a hepatitis B DNA level below 200 IU per millilitre. $^{12}$

Dental professionals living with hepatitis C who have been treated with antiviral therapy can perform exposure prone procedures if they have responded to the treatment by having the antibodies to the hepatitis $\mathrm{C}$ virus but are negative to the hepatitis C RNA virus for at least six months after cessation of treatment. ${ }^{12}$

Dental professionals living with blood borne viruses must be under the joint
The General Dental Council's Standards for the dental team states that the whole dental team has a duty to treat patients fairly, without discrimination and in line with the law. This includes patients who reveal to them that they are living with a blood borne virus. ${ }^{15}$

The General Dental Council standard 4.2 also makes clear that the whole dental team must protect patients' confidentiality including their personal and medical details. Non-registered members of the dental team such as receptionists must be made aware of the importance of maintaining patient confidentiality. ${ }^{15}$ The GDC also outlines the principles for effective complaints handling to enable patients to express any concerns they may have and to enable the dental team to learn from these. ${ }^{15}$

\section{Further resources}

Further information may be obtained from:
- British Dental Association Advice - Infection Control England ${ }^{16}$

- British Dental Association Evidence Summary - Attitude to patients with blood borne viruses. ${ }^{17}$

\section{Checklist to support best practice Access}

Does your practice accept all patients from the community without restrictions?

\section{Policies}

Does your practice have the following policies that are readily accessible to all staff and part of staff induction?

- Confidentiality to ensure security of patient information

- Hand hygiene

- Safe sharps disposal

- Needlestick injuries, including post exposure prophylaxis

- Infection control

- Complaints

- Equality and diversity.

\section{Staff recruitment, induction}

\section{and training}

Is hand hygiene included in your staff induction with regular updated training provided to all staff?

Do contracts of employment at your practice include a statement of the need to ensure patient confidentiality?

Does your practice keep records of staff infection control training, including five hours of enhanced CPD in disinfection and decontamination per GDC cycle?

Have all your practice staff had the standard health clearance checks including hepatitis $\mathrm{B}$ immunisation status and tests for hepatitis $\mathrm{B}$ and $\mathrm{C}$ and HIV as required by national guidance?

Are all members of the dental team familiar with the practice complaints policy?

Do team members in your practice have complaints handling training as recommended by the GDC?

Does your practice take actions to support patients to raise any concerns they may have, and effectively respond to and learn from them?

\section{Practice links}

Does your practice have formal links with an occupational health service to undertake the management of sharps injuries to staff?

Has your practice clarified with the occupational health service the local arrangements for post exposure prophylaxis for staff if needed? 


\section{Practice environment}

Is there an appropriate environment at your practice to ensure that patients can disclose sensitive information?

Does your practice keep a written log of complaints and use this to identify possible areas of improvement in patient care?

Does your practice provide adequate supplies and training in the use of personal protective equipment, disposable gloves, masks and eye protection for all staff?

Is the HTM 01-05 poster illustrating hand hygiene displayed above every hand wash basin at your practice?

\section{Compliance with HTM 01-05}

Does your practice prepare an annual statement of infection control that includes known infection transmission events and actions taken from this, audits undertaken, risk assessments undertaken, staff training and practice policy updates?

Does your practice carry out six-monthly infection audits in line with HTM 01-05?

Is your practice compliant with the essential quality requirements of HTM 01-05?

Is your practice compliant with the best practice requirements of HTM 01-05? If not, do you have a date set to achieve best practice requirements?

1. Public Health England. Towards elimination of HIV transmission, AIDS and HIV-related deaths in the UK. 2017. Available at: https://www.gov.uk/ government/uploads/system/uploads/ attachment_data/file/675809/Towards_ elimination_of_HIV_transmission_AIDS_ and_HIV_related_deaths_in_the_UK.pdf (accessed 31 January 2018).

2. Public Health England. Hepatitis $C$ in the UK 2015 report. 2015. Available at: https:// www.gov.uk/government/uploads/system/ uploads/attachment_data/file/448710/ NEW_FINAL_HCV_2015_IN_THE_UK_ REPORT_28072015_v2.pdf (accessed 1 March 2018).

3. Department of Health. Hepatitis B: migrant health guide. 2017. Available at: https:// www.gov.uk/guidance/hepatitis-b-migranthealth-guide (accessed 1 March 2018).

4. Public Health England. Eye of the needle. United Kingdom surveillance of significant occupational exposures to bloodborne viruses in healthcare workers. 2014. Available at: https://www.gov.uk/ government/uploads/system/uploads/ attachment_data/file/385300/EoN_2014_-_ FINAL_CT_3_sig_occ.pdf (accessed 1 March 2018).

5. Department of Health. Decontamination

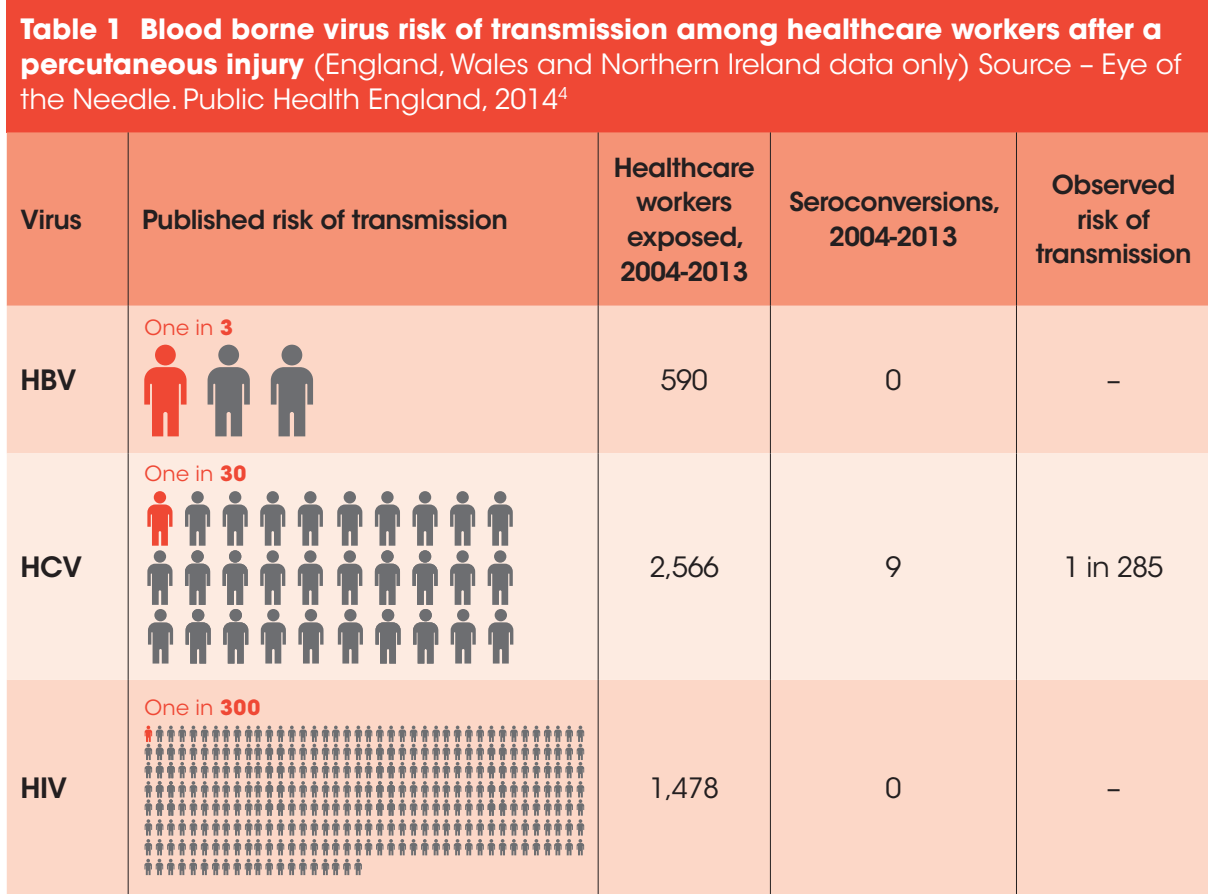

Health Technical Memorandum 01-05: Decontamination in primary care dental practices. 2013. Available at: https://www. gov.uk/government/uploads/system/ uploads/attachment_data/file/170689/ HTM_01-05_2013.pdf (accessed 1 March 2018).

6. Department of Health. Hepatitis B: the green book, chapter 18. 2017. Available at: https://www.gov.uk/government/ publications/hepatitis-b-the-green-bookchapter-18 (accessed 1 March 2018).

7. Health and Safety Executive. Health and Safety (Sharp Instruments in Healthcare) Regulations 2013. Available at: http://www. hse.gov.uk/pubns/hsis7.pdf (accessed 1 March 2018).

8. General Dental Council. Enhanced CPD. 2018. Available at: https://www.gdc-uk.org/ professionals/cpd/enhanced-cpd (accessed 23 February 2018).

9. General Dental Council. Recommended CPD topics. 2018. Available at: https:// www.gdc-uk.org/professionals/cpd/cpdtopics (accessed 25 January 2018).

10. Department of Health. HIV post-exposure prophylaxis - Guidance from the UK Chief Medical Officers' Expert Advisory Group on AIDS. 2008.

11. Department of Health. Hepatitis B Healthcare workers and antiviral therapy. 2007. Available at: http://webarchive. nationalarchives.gov.uk/20130107105354/ http://www.dh.gov.uk/prod_consum_dh/ groups/dh_digitalassets/documents/ digitalasset/dh_073133.pdf (accessed 1 March 2018).

12. Public Health England. Integrated guidance on health clearance of healthcare workers and the management of healthcare workers infected with bloodborne viruses (hepatitis B, hepatitis C and HIV), October 2017. Available at: https://www.gov.uk/ government/uploads/system/uploads/ attachment_data/file/655418/Integrated_ guidance_for_management_of_BBV_in_ HCW_v1.1_October_2017.pdf (accessed 25 January 2018).

13. Equality Act 2010. 2010. Available at: http://www.legislation.gov.uk/ ukpga/2010/15/contents (accessed 1 March 2018).

14. Care Quality Commission. Regulations for service providers and managers. 2017. Available at: http://www.cqc.org. uk/guidance-providers/regulationsenforcement/regulations-service-providersmanagers (accessed 26 October 2017).

15. General Dental Council. Standards for the dental team. 2013. Available at: https:// www.gdc-uk.org/professionals/standards/ team (accessed 1 March 2018).

16. British Dental Association. Infection control - England. 2015.

17. British Dental Association. BDA Evidence Summary: Attitude to patients with blood borne viruses. 2013.

\section{CPD questions}

This article has four CPD questions attached to it which will earn you one hour of verifiable CPD. To access the free BDA CPD hub, go to https:// cpd.bda.org/login/index.php

bdjteam201875 